Pacific Journal of Mathematics

RANGES AND INVERSES OF PERTURBED LINEAR 


\title{
RANGES AND INVERSES OF PERTURBED LINEAR OPERATORS
}

\author{
SEYMOUR GOLDBERG
}

1. Introduction. Let $X$ and $Y$ denote normed linear spaces and let $T \neq 0$ be a linear operator with domain $D(T) \subset X$ and range $R(T) \supset Y$. In this paper, $D(T)$ is not required to be dense in $X$ and $T$ need not be continuous. Furthermore, $X$ and $Y$ shall be assumed complete only when necessary. Under these general conditions, we investigate some invariant properties of the range and inverse of $T$ when $T$ is perturbed by a bounded linear operator $A$. For example, it is shown that if the range of $T$ is not dense in $Y$ and $T$ has a bounded inverse, then $T+A$ has the same properties provided that $D(A) \supset D(T)$ and the norm of $A$ is sufficiently small. In addition, a theorem of Yood ([5], Th. 2.1) is generalized with some of the proofs simplified.

Definition. Let $X_{1}=\overline{D(T)} \subset X$. When $X_{1}$ is considered as a normed linear space, the conjugate transformation $T^{\prime}$ is defined as follows: Its domain $D\left(T^{\prime}\right)$ consists of the set of all $y^{\prime}$ in the conjugate space $Y^{\prime}$ for which $y^{\prime} T$ is continuous on $D(T)$; for such a $y^{\prime}$ we define $T^{\prime} y^{\prime}=x^{\prime}$ where $x^{\prime}$ is the unique bounded linear extension of $y^{\prime} T$ to $X_{1}$; that is, $x^{\prime}$ is in the conjugate space $X_{1}^{\prime}$ of $X_{1}$.

The above notations shall be retained throughout the discussion.

\section{Ranges and inverses of $T+A$.}

Lemma 1. If $T$ has a bounded inverse, then so does $T+A$ whenever $\|A\|<\left\|T^{-1}\right\|^{-1}$.

Proof. $\|(T+A) x\|>\left(\left\|T^{-1}\right\|^{-1}-\|A\|\right)\|x\|$.

Theorem 1. If $\overline{R(T)}=Y$ and $T$ has a bounded inverse, then $\overline{R(T+A)}=Y$ and $T+A$ has a bounded inverse whenever $\|A\|<\left\|T^{-1}\right\|^{-1}$ and $D(T) \subset D(A)$.

Proof. By [4] Th. 1.4, $\left(T^{\prime}\right)^{-1}=\left(T^{-1}\right)^{\prime}$ exists and is continuous on $X_{1}^{\prime}$. Hence from the lemma we conclude that $(T+A)^{\prime}=T^{\prime}+A^{\prime}$ has a bounded inverse since $\left\|A^{\prime}\right\|=\|A\|<\left\|T^{-1}\right\|^{-1}=\left\|\left(T^{\prime}\right)^{-1}\right\|^{-1}$. The theorem now follows from [4] Th. 1.2.

If for $X=Y$, the resolvent of a linear operator $T$ is defined as the set of scalars $\lambda$ such that $(T-\lambda I)^{-1}$ exists and is continuous on a

Received February 19, 1959. 
domain dense in $X$, then the following corollary is an immediate result of the theorem.

COROLlaRY. The resolvent of a linear operator is open.

Definition. For each $z \neq 0$ in $Y$, let

$$
m_{z}(T)=\sup \{k /\|z-T x\| \geqq k\|T x\|, x \in D(T)\} .
$$

We define $m(T)=\sup _{0 \neq z \in Y} m_{z}(T)$.

REMARK. $m(T) \leqq 1$; This follows from the fact that for $T x \neq 0$ and for each $z \in Y,\|z-T \alpha x\| /\|T \alpha x\| \leqq 1+\|z\| /\|T \alpha x\| \rightarrow 1$ as $|\alpha| \rightarrow \infty$.

Lemma 2. Let $Y$ be complete. Then $\overline{R(T)}=Y$ if and only if $m(T)=0$.

Proof. If $\overline{R(T)}=Y$, it is easy to see that $m(T)=0$. Suppose there exists an element $y_{0} \in Y$ which is not in $\overline{R(T)}$. The 1-dimensional linear manifold $\left[y_{0}\right]$ spanned by $y_{0}$ and the linear manifold $\left[y_{0}\right]+\overline{R(T)}$ are closed in $Y$; moreover, $\left[y_{0}\right] \cap \overline{R(T)}=(0)$. Hence by [2] Th. 2.1, there exists a $k>0$ such that $\left\|y_{0}-y\right\| \geqq k\|y\|$ for all $y \in R(T)$; that is, $m(T)>0$.

Theorem 2. If $\overline{R(T)} \neq Y$ and $T$ has a bounded inverse, then $\overline{R(T+A)} \neq Y$ and $T+A$ has a bounded inverse whenever $\|A\|<m(T) /\left\|T^{-1}\right\|$, and $D(T) \subset D(A)$.

Proof. Clearly there is no loss of generality if the theorem is proved for the completion $\tilde{Y}$ of $Y$. Thus it may be assumed that $Y$ is complete. We now simplify and apply an argument given by Yood [5, p. 489]. From Lemma 1, $T+A$ has a bounded inverse. By Lemma 2 , there exists, for each $\varepsilon>0$, an element $y_{0} \in Y$ but not in $\overline{R(T)}$ such that

$$
\left\|y_{0}-T x\right\| \geqq(m(T)-\varepsilon)\|T x\| \text { for all } x \in D(T) \text {. }
$$

Suppose that the theorem is not true. Then $y_{0} \in \overline{R(T+A)}=Y$ and thus we may choose an element $x \in D(T)$ so that

$$
\left\|(T+A) x-y_{0}\right\|<\min \left(\varepsilon d,\left\|y_{0}\right\|\right),
$$

where $d$ is the distance between $y_{0}$ and $\overline{R(T)}$. In particular, 


$$
\left\|(T+A) x-y_{0}\right\|<\varepsilon d \leqq \varepsilon\left\|y_{0}-T x\right\| \text { and } x \neq 0 .
$$

From (1) and (2),

$$
\begin{aligned}
\|A\|\|x\| & \geqq\|A x\| \geqq\left\|T x-y_{0}\right\|-\left\|y_{0}-(T+A) x\right\|>(1-\varepsilon)\left\|y_{0}-T x\right\| \\
& \geqq(1-\varepsilon)(m(T)-\varepsilon)\|T x\| \geqq\left\|T^{-1}\right\|^{-1}(1-\varepsilon)(m(T)-\varepsilon)\|x\| .
\end{aligned}
$$

Since $\varepsilon>0$ was arbitrary, $\|A\| \geqq\left\|T^{-1}\right\|^{-1}(m(T))$ which is impossible.

Lemma 3. Suppose $X$ and $Y$ are complete. If $T$ is a closed linear operator, then $R(T)=Y$ and $T^{-1}$ does not exist if and only if $\overline{R\left(T^{\prime}\right)} \neq X_{1}^{\prime}$ and $T^{\prime}$ has a bounded inverse.

Proof. This follows from the "state diagram" for closed operators [1].

Theorem 3. Suppose $X$ and $Y$ are complete. If $T$ is closed, $R(T)=Y$ and $T^{-1}$ does not exist, then $R(T+A)=Y$ and $(T+A)^{-1}$ does not exist whenever $D(T) \subset D(A)$ and $A<m\left(T^{\prime}\right) /\left\|\left(T^{\prime}\right)^{-1}\right\|$.

Proof. By Lemma 3, $\overline{R\left(T^{\prime}\right)} \neq X_{1}^{\prime}$ and $T^{\prime}$ has a bounded inverse. Futhermore, $D\left(A^{\prime}\right)=Y^{\prime} \supset D\left(T^{\prime}\right)$ and $T^{\prime} \neq 0$ since $D\left(T^{\prime}\right)$ is total ([4] Th. 1.1). From Theorem 2, it is clear that $\overline{R\left(T^{\prime}+A^{\prime}\right)} \neq X_{1}^{\prime}$ and $T^{\prime}+A^{\prime}$ has a bounded inverse. Since $T^{\prime}+A^{\prime}=(T+A)^{\prime}$ and $T+A$ is closed, the theorem follows from Lemma 3 .

3. A generalization of a theorem. In ([5] Th. 2.1), Yood proves a theorem about the range of a bounded linear transformation $T$ and its conjugate $T^{\prime}$, where $T$ maps Banach Space $X$ into Banach space $Y$. We now generalize the theorem by requiring instead that $T$ be a closed linear operator on $D(T)$. The results are stated in a different but more precise form than in [5].

Definition. If $T$ has a bounded inverse, let $K(T)=\left\|T^{-1}\right\|$, otherwise let $K(T)=0$. We now define a number $\alpha(T)$ as follows:

$$
\begin{aligned}
\alpha(T) & =\min \left(\left(m(T), \frac{m(T)}{K(T)}\right) \text { if } m(T)>0\right. \\
& =\infty \text { if } m(T)=0 .
\end{aligned}
$$

$\alpha\left(T^{\prime}\right)$ shall be defined in a similar manner.

TheOREM 4. Suppose $X$ and $Y$ are complete. Let $T$ be a closed linear transformation and let $A$ represent a bounded linear transform- 
ation such that $D(A) \supset D(T)$. Then the following statements concerning $T$ are equivalent.

(1) Either $T$ has bounded inverse or $R(T)=Y$.

(2) $\overline{R\left(T^{\prime}+A^{\prime}\right)} \subset R\left(T^{\prime}\right)$ if $\|A\|<\alpha\left(T^{\prime}\right)$.

(3) $R\left(T^{\prime}+A^{\prime}\right) \subset R\left(T^{\prime}\right)$ if $\|A\|<\alpha\left(T^{\prime}\right)$.

(4) $R\left(T^{\prime}\right)$ is not a proper dense subset of $X_{1}^{\prime}$ and $\|A\|<\alpha\left(T^{\prime}\right)$ implies that $\overline{R\left(T^{\prime}+A^{\prime}\right)} \subset R\left(T^{\prime}\right)$.

(5) $R\left(T^{\prime}\right)$ is not a proper dense of $X_{1}^{\prime}$ and $\|A\|<\alpha\left(T^{\prime}\right)$ implies that $R\left(T^{\prime}+A^{\prime}\right) \subset R\left(T^{\prime}\right)$.

(6) $\overline{R(T+A)} \subset R(T)$ if $\|A\|<\alpha(T)$.

(7) $R(T+A) \subset R(T)$ if $\|A\|<\alpha(T)$.

(8) $R(T)$ is not a proper dense subset of $Y$ and $\|A\|<\alpha(T)$ implies that $\overline{R(T+A)} \subset R(T)$.

(9) $R(T)$ is not a proper dense subset of $Y$ and $\|A\|<\alpha(T)$ implies that $R(T+A) \subset R(T)$.

Proof. (1) implies (2): ( $T$ need not be closed): If $T$ has a bounded inverse, then by [1] $R\left(T^{\prime}\right)=X_{1}^{\prime} \supset R\left(T^{\prime}+A^{\prime}\right)$ for all $A$. If $T$ has no bounded inverse, then $R(T)=Y$ so that $R\left(T^{\prime}\right) \neq X_{1}^{\prime}$ and $T^{\prime}$ has a bounded inverse by [1]. Since $T^{\prime}$ is closed, it follows that $R\left(T^{\prime}\right)$ is closed; i.e. $m\left(T^{\prime}\right)>0$. If (2) is false, there exists an $x_{0}^{\prime} \in \overline{R\left(T^{\prime}+A^{\prime}\right)}$ but at a positive distance $d$ from $R\left(T^{\prime}\right)$. By the argument as in Theorem $2,\|A\|=\left\|A^{\prime}\right\| \geqq \frac{m\left(T^{\prime}\right)}{K\left(T^{\prime}\right)} \geqq \alpha\left(T^{\prime}\right)>\|A\|$ which is impossible.

(2) implies (3). Obvious

(3) implies (1): (cf. [5]): If $R(T) \neq Y$ and $T$ has no bounded inverse, then we show that (3) fails to hold. By [1], $R\left(T^{\prime}\right) \neq X_{1}^{\prime}$ and $T^{\prime}$ has no bounded inverse. Therefore, we may choose an element $x_{0}^{\prime} \in X_{1}^{\prime}$, $\left\|x_{0}^{\prime}\right\|=1$ and $x_{0}^{\prime} \notin R\left(T^{\prime}\right)$. For each $\varepsilon>0$, there exists an element $y_{0}^{\prime} \in D\left(T^{\prime}\right)$ such that $\left\|y_{0}^{\prime}\right\|=1,\left\|T^{\prime} y_{0}^{\prime}\right\|<\varepsilon$ and an element $y_{0}$ such that $\left\|y_{0}\right\|=1, y_{0}^{\prime} y_{0}=\beta$ is real and $1 \geqq \beta \geqq 1 / 2$. Let $A$ be defined by $A x=\varepsilon\left(x_{0}^{\prime} x-(\varepsilon \beta)^{-1} T^{\prime} y_{0}^{\prime} x\right) y_{0}$ for $x \in D(T)$. Hence

$$
A^{\prime} y_{0}^{\prime}=\varepsilon y_{0}^{\prime} y_{0}\left(x_{0}^{\prime}-(\varepsilon \beta)^{-1} T^{\prime} y_{0}^{\prime}\right)=\varepsilon \beta x_{0}^{\prime}-T^{\prime} y_{0}^{\prime},
$$

so that

$$
\left(T^{\prime}+A^{\prime}\right) y_{0}^{\prime}=\varepsilon \beta x_{0}^{\prime} \notin R\left(T^{\prime}\right) . \quad \text { Moreover, }\|A\| \leqq \varepsilon\left(1+\frac{1}{\beta}\right) \leqq 3 \varepsilon .
$$

Since $\varepsilon>0$ was arbitrary, it follows that (3) does not hold.

(4) and (5) implies (1): Follows from the above argument.

(1) implies (4) and (5): ( $T$ need not be closed): This follows from the fact that 
(1) implies that $R\left(T^{\prime}\right)$ is closed and also that (1) implies (2).

(1) implies (6): If $R(T)=Y$, then (6) is satisfied. Suppose $R(T) \neq Y$ but that $T$ has a bounded inverse. Hence $R(T)$ is closed so that $m(T)>0$. If (6) is false, there exists an element $y_{0} \varepsilon Y=\overline{R(T+A)}$ but $y_{0} \notin R(T)$. The remaining argument is now as in Theorem 2 .

(6) implies (7): Obvious

(7) implies (1): If $R(T) \neq Y$ and $T$ has no bounded inverse, then for $\varepsilon>0$, there exists an element $x_{0} \in D(T),\left\|x_{0}\right\|=1$ such that $\left\|T x_{0}\right\|<\varepsilon$. An element $x_{0}^{\prime} \in X_{1}^{\prime}$ is chosen so that $\left\|x_{0}^{\prime}\right\|=1$ and $x_{0}^{\prime} x_{0}=1$. Suppose that $y \notin R(T)$ and $\|y\|=1$. We define $A$ by the relation

$$
A x=\varepsilon x_{0}^{\prime} x\left(y-\varepsilon^{-1} T x_{0}\right), x \in D(T) .
$$

Then $(T+A) x_{0}=\varepsilon y \notin R(T)$. Moreover, $\|A\|<2 \varepsilon$. Since $\varepsilon>0$ is arbitrary, (7) cannot hold. Thus the assertion is proved.

(8) and (9) are equivalent to (1): This is shown in the same way that (4) and (5) were shown equivalent to (1).

If there is no restriction put on the inverse but only on the range of $T$, we may still infer something about the range of $T+A$. In fact, $A$ need not be continuous. The following theorem illustrates this.

Theorem 5. Suppose $X$ and $Y$ are complete. If $T$ is a closed linear operator with a closed range, then there exists a $\rho>0$ such that $T+A$ is also a closed linear operator with a closed range whenever $A$ is a linear operator (not necessarily continuous) with $D(A) \supset D(T)$ and $\|A x\| \leqq \rho(\|x\|+\|T x\|)$ for every $x \in D(T)$.

Proof. We introduce another norm $\|x\|_{1}$, on $D(T)$ by defining $\|x\|_{1},=\|x\|+\|T x\| . \quad D_{1}$ shall denote $D(T)$ with this new norm. Since $X$ and $Y$ are complete and $T$ is closed, it is easy to see that $D_{1}$ is a complete normed linear space. Moreover, $T_{1}$ as a transformation of $D_{1}$ into $Y$ is bounded and has an inverse. Thus by the closed graph theorem, $T^{-1}$ is bounded; i.e. there exists an $m>0$ such that $\|T x\| \geqq$ $m(\|x\|+\|T x\|)$ for $x \in D_{1}$. Choose $\rho>0$ so that $1>\rho$ and $m-\rho>0$. Thus $\|(T+A) x\| \geqq(m-\rho)(\|x\|+\|T x\|)$, whence $T+A$ has a bounded inverse from $R(T+A)$ onto $D_{1}$. Clearly $T+A$ is continuous on $D_{1}$. Since defining a new norm in $D(T)$ does not alter the situation in $Y$, it follows that $R(T+A)$ is closed. In [3], Nagy proves that $T+A$ is a closed operator from $D(T)$ into $Y$, which completes the proof of the theorem.

\section{BIBLIOGRAPHY}

1. S. Goldberg, Linsar operators and their conjugates, Pacific J. Math., 9 (1959), 69-79. 
2. E. R. Lorch, On a calculus of operators in reflexive vector spaces, Trans. Amer. Math Soc., 45 (1939), 217-234.

3. B. Sz. Nagy, On the stability of the index of unbounded linear transformations, Acta Math. Sci. Hungaricae, 3 (1952), 49-52.

4. R. S. Phillips, The adjoint semi-group, Pacific J. Math., 5 (1955), 269-282.

5. B. Yood, Transformations between Banach Spaces in the uniform topology, Ann. of Math., 50 (1949), 486-503.

\section{HEBREW UNIVERSITY}




\section{PACIFIC JOURNAL OF MATHEMATICS}

\section{EDITORS}

\section{David Gilbarg}

Stanford University Stanford, California

\section{R. A. Beaumont}

University of Washington

Seattle 5, Washington

\section{A. L. Whiteman}

University of Southern California Los Angeles 7, California

L. J. Paige

University of California

Los Angeles 24, California

\section{ASSOCIATE EDITORS}

E. F. BECKENBACH
C. E. BURGESS
E. HEWITT
A. HORN

A. HORN

\author{
V. GANAPATHY IYER \\ R. D. JAMES \\ M. S. KNEBELMAN \\ L. NACHBIN
}

I. NIVEN

T. G. OSTROM

H. L. ROYDEN

M. M. SCHIFFER
E. G. STRAUS

G. SZEKERES

F. WOLF

K. YOSIDA

\section{SUPPORTING INSTITUTIONS}

\author{
UNIVERSITY OF BRITISH COLUMBIA \\ CALIFORNIA INSTITUTE OF TECHNOLOGY \\ UNIVERSITY OF CALIFORNIA \\ MONTANA STATE UNIVERSITY \\ UNIVERSITY OF NEVADA \\ OREGON STATE COLLEGE \\ UNIVERSITY OF OREGON \\ OSAKA UNIVERSITY \\ UNIVERSITY OF SOUTHERN CALIFORNIA
}

\author{
STANFORD UNIVERSITY \\ UNIVERSITY OF TOKYO \\ UNIVERSITY OF UTAH \\ WASHINGTON STATE COLLEGE \\ UNIVERSITY OF WASHINGTON \\ * * * * \\ AMERICAN MATHEMATICAL SOCIETY \\ CALIFORNIA RESEARCH CORPORATION \\ HUGHES AIRCRAFT COMPANY \\ SPACE TECHNOLOGY LABORATORIES
}

Mathematical papers intended for publication in the Pacific Journal of Mathematics should be typewritten (double spaced), and the author should keep a complete copy. Manuscripts may be sent to any one of the four editors. All other communications to the editors should be addressed to the managing editor, L. J. Paige at the University of California, Los Angeles 24, California.

50 reprints per author of each article are furnished free of charge; additional copies may be obtained at cost in multiples of 50 .

The Pacific Journal of Mathematics is published quarterly, in March, June, September, and December. The price per volume (4 numbers) is $\$ 12.00$; single issues, $\$ 3.50$. Back numbers are available. Special price to individual faculty members of supporting institutions and to individual members of the American Mathematical Society: $\$ 4.00$ per volume; single issues, $\$ 1.25$.

Subscriptions, orders for back numbers, and changes of address should be sent to Pacific Journal of Mathematics, 2120 Oxford Street, Berkeley 4, California.

Printed at Kokusai Bunken Insatsusha (International Academic Printing Co., Ltd.), No. 6, 2-chome, Fujimi-cho, Chiyoda-ku, Tokyo, Japan.

PUBLISHED BY PACIFIC IOURNAL OF MATHEMATICS, A NON-PROFIT CORPORATION

The Supporting Institutions listed above contribute to the cost of publication of this Journal, but they are not owners or publishers and have no responsibility for its content or policies. 


\section{Pacific Journal of Mathematics}

\section{Vol. 9, No. $3 \quad$ July, 1959}

Errett Albert Bishop, A minimal boundary for function algebras . . . . . . . . . . . . 629

John W. Brace, The topology of almost uniform convergence . . . . . . . . . . . . 643

Cecil Edmund Burgess, Chainable continua and indecomposability .......... 653

L. Carlitz, Multiplication formulas for products of Bernoulli and Euler

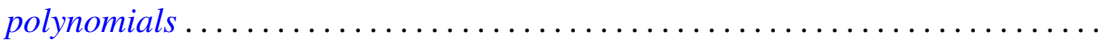

Eckford Cohen, A class of residue systems (mod $r$ ) and related arithmetical

functions. II. Higher dimensional analogues ....................

Shaul Foguel, Boolean algebras of projections of finite multiplicity . . . . . . . . . .

Richard Robinson Goldberg, Averages of Fourier coefficients .................

Seymour Goldberg, Ranges and inverses of perturbed linear operators .

Philip Hartman, On functions representable as a difference of convex functions ....

Milton Vernon Johns, Jr. and Ronald Pyke, On conditional expectation and

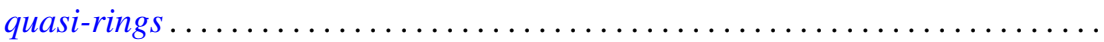

Robert Jacob Koch, Arcs in partially ordered spaces ....................

Gregers Louis Krabbe, A space of multipliers of type $L^{p}(-\infty, \infty) \ldots \ldots \ldots \ldots$

John W. Lamperti and Patrick Colonel Suppes, Chains of infinite order and their

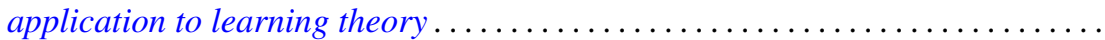

Edith Hirsch Luchins, On radicals and continuity of homomorphisms into Banach

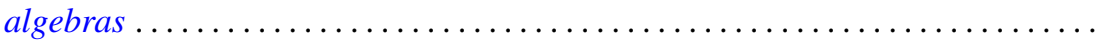

T. M. MacRobert, Multiplication formulae for the E-functions functions of their parameters.

Michael Bahir Maschler, Classes of minimal and representative domains and their kernel functions.

William Schumacher Massey, On the imbeddability of the real projective spaces in Euclidean space.

Thomas Wilson Mullikin, Semi-groups of class $\left(C_{0}\right)$ in $L_{p}$ determined by parabolic differential equations

Steven Orey, Recurrent Markov chains

Ernest Tilden Parker, On quadruply transitive groups ........ . .

Calvin R. Putnam, On Toeplitz matrices, absolute continuity, and unitary

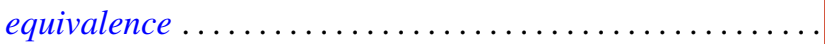

Helmut Heinrich Schaefer, On nonlinear positive operators.

Robert Seall and Marion Wetzel, Some connections between continued fractions and convex sets

Robert Steinberg, Variations on a theme of Chevalley

Olga Taussky and Hans Zassenhaus, On the similarity transformation between a

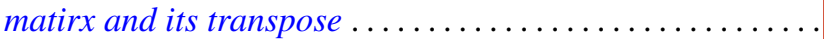

Emery Thomas, The suspension of the generalized Pontrjagin cohomology

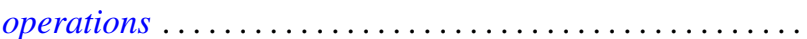

Joseph L. Ullman, On Tchebycheff polynomials ..................... 913

Richard Steven Varga, Orderings of the successive overrelaxation scheme ........ 925

Orlando Eugenio Villamayor, Sr., On weak dimension of algebras . 